\title{
Effect of Electrodeposition Parameters on Morphology of Copper Thin Films
}

\author{
Jaishree Mathur, and Manish Gupta \\ ${ }^{I}$ (Department of Physics, Jawahar Navodaya Vidyalaya, Mandaphia, Chittorgarh, Rajasthan, India) \\ ${ }^{2}$ (Project director Department of Science and Technology, Jaipur, Rajasthan)
}

\begin{abstract}
In this work a simple approach of highly dispersed electro catalytically active copper nano-structured thin film has been electrodeposited on conducting Indium Tin Oxide coated (ITO) glass plate from non cyanide acidic electrolyte. The influence of deposition variables such as: $\mathrm{pH}$, deposition time and current density on film composition, morphology and crystal orientation associated with the growth of the film was investigated. The copper dendrites are characterized by Optical microscopy, SEM, X-Ray Diffraction, Electrical resistivity as well as by cyclic voltammetry under different conditions. Optimal conditions for uniform growth of nanoparticles well-dispersed, golden shiny cubic copper on the ITO glass plate have been determined.
\end{abstract}

Keywords: - Electrodeposition, morphology, Scanning electron microscopy, XRD, Electrical conductivity of thin film.

\section{INTRODUCTION}

The Copper is electrodeposited for numerous engineering and decorative applications requiring wide range of mechanical and physical properties. This range extends from properties superior to full hard, wrought copper to properties equivalent to an annealed, pure copper, resistivity, elastic modulus and coefficient of thermal expansion are important physical properties which can be controlled. The desired properties will be obtained only when the plating baths and operating conditions are properly selected [1-3]. Copper is the metal of choice for interconnects because it addresses issues such as performances of integrated circuits with the continuing trend toward miniaturization of devices, successful applications of copper electrodeposition in nano interconnects could strongly depend on its surface roughness scattering. The increase in electronic resistivity due to surface scattering is a fundamental quantum mechanics problem, while the elimination of surface roughness scattering and grain boundary scattering is a morphological issue which can be controlled by fabrication technique [4]. Copper thin films are also used in the multilayer sandwiches of GMR hard disk read heads. Among various methods of thin film deposition of copper onto substrates such as PVD, CVD and sputtering [5], The electrochemical methods have proven to be at least expensive, highly productive and readily adoptable [6-7]. The electrodeposition of materials allows formation of thin layers, like monolayers, with the added advantage of a better kinetic control [8]; this is expected because there is effective control over the coverage of the deposited material monolayer. Electrodeposition of copper from cyanide solutions is a long established industrial practice [9-11]. But this process is now used infrequently, not only because of its toxicity but also due to photo resistive attack during the plating process. Thus an extensive search has been made for satisfactory alternative electrolytes. In this context we have undertaken a complete study of copper electrodeposition on ITO coated glass substrate in $\mathrm{CuSO} 4.5 \mathrm{H} 2 \mathrm{O}$ solution by varying different deposition parameters. The work described here illustrates how the sulfate and $\mathrm{OH}$ - ions can modify the morphology of the copper electrodeposits, undertaking the dynamics of these processes is essential in the design of chemical systems for practical applications.

\section{EXPERIMENTAL DETAILS}

Electrolytic solution was prepared using CuSO4.5H2O (Sigma Aldrich) 99.99\% pure and deionized water (milipore) with concentration of $0.5 \mathrm{M}$ of solution, $0.20 \mathrm{M}$ sodium acetate and $\mathrm{NaOH}$. Solution was adjusted to $\mathrm{pH} 1-5$ by adding diluted reagent grade sulfuric acid. Substrate were cleaned and rinsed with distilled water and acetone before deposition of the films. Here Copper plate was used as counter electrode, ITO as working electrode and $\mathrm{Ag} / \mathrm{AgCl}$ as reference electrode. All experiments were carried out at room temperature. Electrodeposition cell was designed and constructed manually in the laboratory.

Thin films of copper have been electrodeposited by varying deposition parameters as follows:

(i) Keeping current density and $\mathrm{pH}$ of the electrolyte as constant but varying deposition time.

(ii) Keeping current density and deposition time as constant but varying $\mathrm{pH}$ of the electrolytic solution.

(iii) Keeping deposition time and $\mathrm{pH}$ as constant but varying current density.

All above variations are done at room temperature. 
These thin films are characterized by X-ray diffraction, SEM, optical microscopy, cyclic voltammetry and surface resistivity measurements.

\section{RESULTS AND DISCUSSION}

\subsection{Keeping $\mathrm{pH}$ and deposition time as constant but varying current density}

Here thin films of copper are electrodeposited at $\mathrm{pH}=5$ and deposition time was kept for 10 minutes with concentration of electrolyte as 0.5 M. In Fig. 3.1 the optical micrographs shows that as the current density increases, coalescence is more [12]. At high constant current density of $1.2 \mathrm{mAcm}^{-2}$ the morphology of copper particles is similar to that of the particles formed at $0.5 \mathrm{mAcm}^{-2}$. However the particle sizes are not uniform and most of them are as small as only $100 \mathrm{~nm}$. At a very high current density of $1.6 \mathrm{mAcm}^{-2}$, the edges and corners of the roundest nuclei grow faster than their other regions and finally grow into copper nanosheets The SEM results (as shown in Fig. 3.2) that the growth of copper nanostructure can be regarded as an instantaneous nucleation process. This shows that due to increase in current density of $1.6 \mathrm{mAcm}^{2}$, the size of cluster decreased gradually and the deposits obtained were clear, uniform and golden. Here sulfate anions act as brighteners.

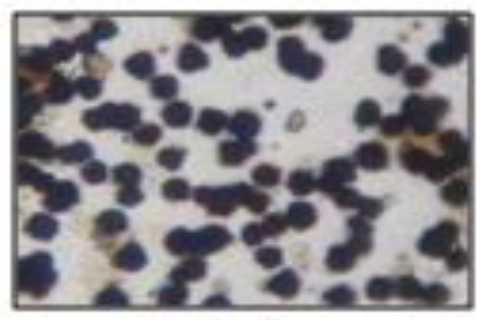

(a)

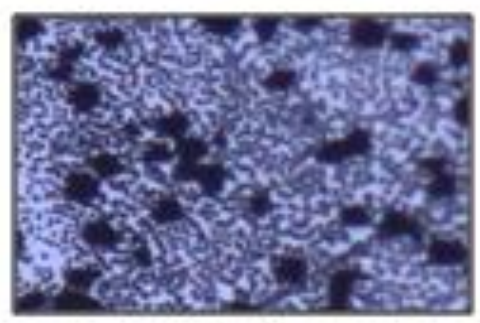

(c)

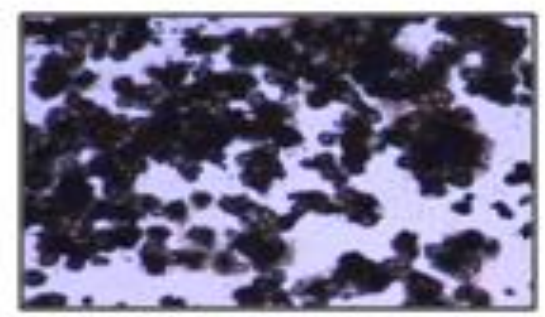

(b)

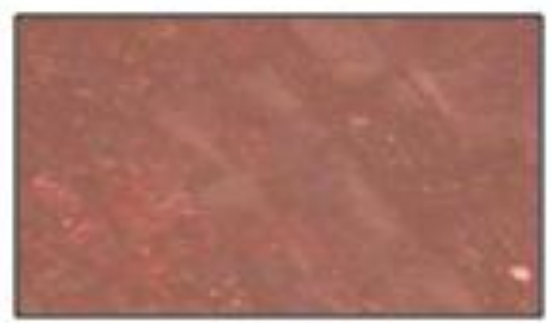

(d)

Figure 3.1 Optical micrographs of Films electrodeposited at deposition time 10 minutes and current density (a) $0.5 \mathrm{mAcm}^{-2}$, (b) $0.8 \mathrm{mAcm}^{-2}$ (c) $1.2 \mathrm{mAcm}^{-2}$ and (d) $1.6 \mathrm{mAcm}^{-2}$

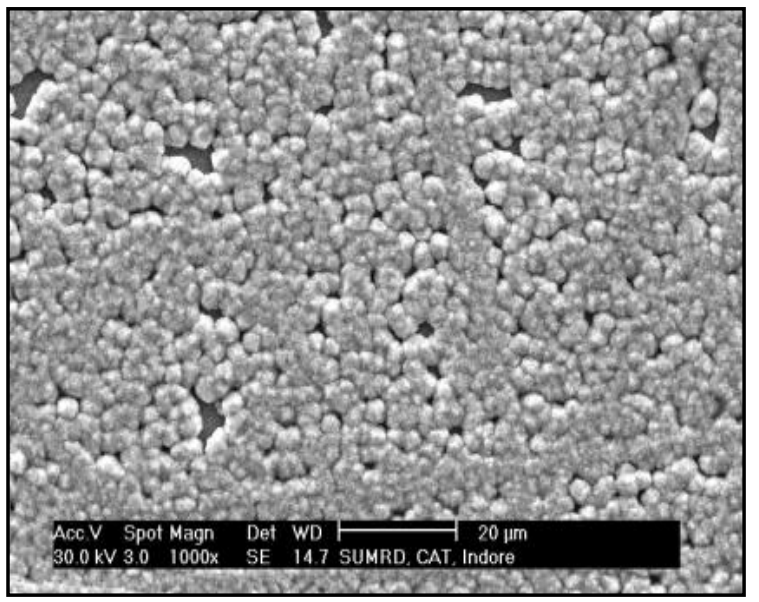

Figure3.2 SEM of electrodeposited copper thin films deposited at current density $1.6 \mathrm{mAcm}^{-2}$ at $\mathrm{pH}=5$ and deposition time 10 minutes.

3.2 Keeping current density and deposition time as constant but varying $\mathrm{pH}$ of the electrolytic solution 
In order to study the role of $\mathrm{pH}$ in the electro deposition of $\mathrm{Cu}$ thin films $\mathrm{pH}$ is varied in the range from 3 to 13 . Concentration of the electrolytic solution was $0.5 \mathrm{M}$ current density was kept at $1.6 \mathrm{mAcm}^{-2}$ and deposition time for 10 minutes. It is cleared from Fig. 3.3 that at $\mathrm{pH}=3$, copper was deposited in the form of equally sized and somewhat rounded grains. At $\mathrm{pH}=4$, the grains were no longer equally sized. Some of the grains at $\mathrm{pH}=4$ were of quite larger size than at $\mathrm{pH}=3$. Thus $\mathrm{pH}$ increase was responsible for the grain shapes and the decrease of surface nuclei population density. The surface morphology is found to be $\mathrm{pH}$ dependent. It is observed that $\mathrm{Cu}$ film deposited at $\mathrm{pH}=5$ exhibits cubic structure. As $\mathrm{pH}$ increases from 5 to 13 the grain size of the film is found to be decreased. It is due to the role of rate of deposition. The rate of deposition increased gradually up to $\mathrm{pH}=4$ and then increased steeply for $\mathrm{pH}$ values exceeding 4 . Such higher rate of deposition caused the change in orientation and reduction in grain size at $\mathrm{pH}=9$. During such grain size reduction the shape of the grains gets damaged and hence it changes from cubic to fibrous structure at $\mathrm{pH} 13$ as shown in Fig. 3.4. Further if the deposition was carried out at $\mathrm{pH}$ greater than 5 , the grains with well defined shape could not be detected. Instead these films showed surfaces with a spongy looking texture as shown in Fig. 3.3(c). An increase in $\mathrm{pH}$ value results in increase in copper concentration in the film with improved uniformity. As the $\mathrm{pH}$ value increases cathode potential increases and hence more copper gets electrodeposited in the film. The films which are grown at a $\mathrm{pH}$ value 5.0 exhibit better physical properties. The SEM micrographs show decrease in grain size with an increase in $\mathrm{pH}$ value in Figure 3.3. A fine grained nanostructure is observed at a $\mathrm{pH}$ value of 5.

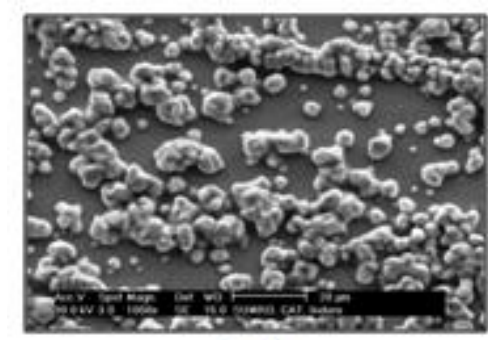

(a)

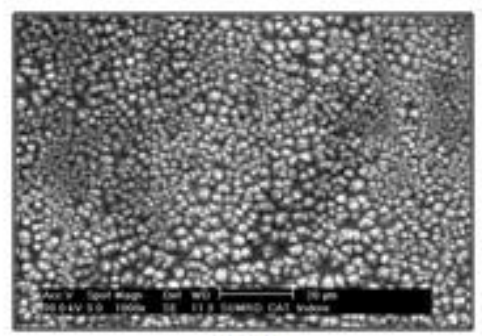

(b)

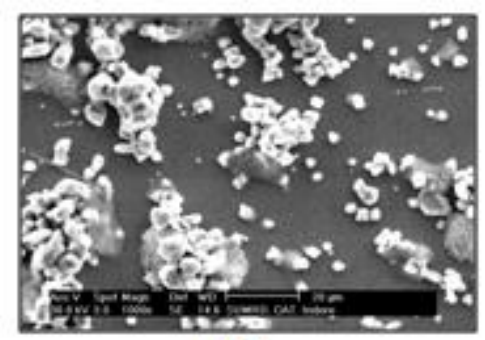

(c)

Figure 3.3 SEM of electrodeposited copper thin films deposited at $\mathrm{pH}$ (a) 4.0 (b) 5.0 and (c) $\mathrm{pH}=9$.

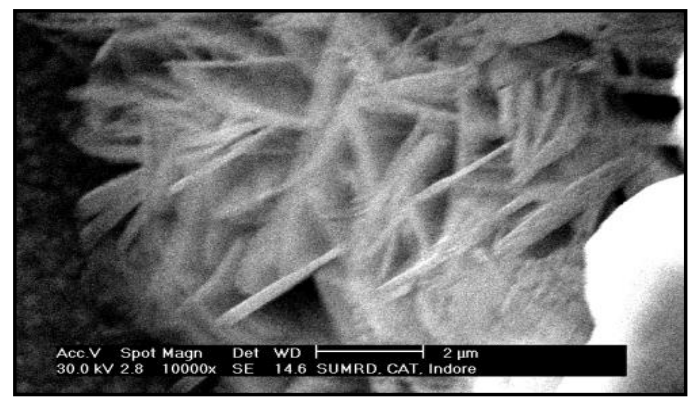

Figure 3.4 SEM of electrodeposited copper film deposited at $\mathrm{pH}=13$ showing fibrous structure

\subsection{Keeping current density, $\mathrm{pH}$ of the electrolyte as constant but varying deposition time}

In this case current density and $\mathrm{pH}$ of the solution was kept as constant and deposition time is varied. It is found that at low current density if deposition time is more, thickness of film increases, due to greater number of particles reaching the cathode and depositing on it. For longer deposition time, at higher current density, the film thickness achieves a maximum and then decreases due to larger amount of evolved hydrogen, which accumulates on the cathode and causes more pores in the deposited film. It can be concluded that optimal deposition time is 20 minute for an applied current density of $1.6 \mathrm{mAcm}^{-2}$. The optical micrograph of copper film obtained under the conditions is represented in Fig. 3.5.

At the very beginning of the deposition process, the copper particles are attracted to the cathode surface. However a large percentage of film surfaces are covered by pores due to large number of pores existing in the film as a result of the hydrogen evolution reaction on the cathode. After a few seconds, the pores are filled with copper particles and consequently film porosity decreases and achieves a minimum value [13]. During further deposition, the film porosity increases but not significantly, due to the larger amount of evolved hydrogen [14]. This shows that this is the case of instantaneous nucleation. As instantaneous nucleation corresponds to a slow growth of nuclei on a small number of active sites, all activated at the same time [15]. 


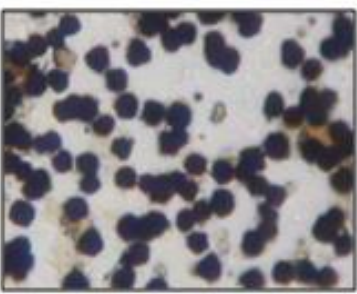

(a)

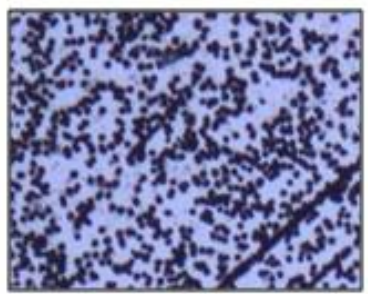

(b)

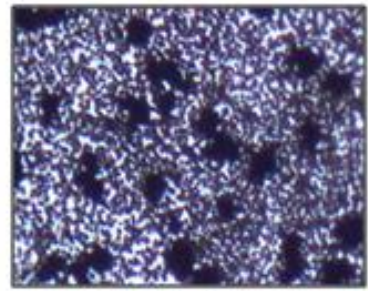

(c)

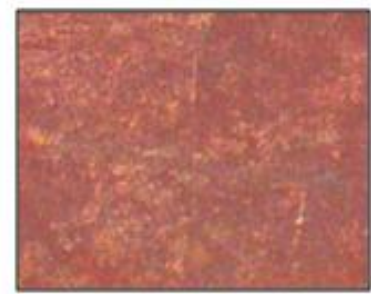

(d)

Figure 3.5 Thin films of Copper deposited at $1.6 \mathrm{mAcm}^{-2}$ current density at deposition time (a)5min.(b) $10 \mathrm{~min}$. (c) 15 min. and (d) $20 \mathrm{~min}$.

Fig. 3.6 shows XRD pattern of copper electrodeposited film for 20 minute at current density 0.5 $\mathrm{mAcm}^{-2}, 0.8 \mathrm{mAcm}^{-2}$ and $1.6 \mathrm{mAcm}^{-2}$ with approximate thickness $550 \mathrm{~nm}, 600 \mathrm{~nm}$ and $700 \mathrm{~nm}$ respectively on ITO substrate confirmed the formation of crystalline $\mathrm{Cu}$ with peaks (111), (200) and (220). Here some peaks are observed between $25^{\circ}$ to $40^{\circ}$ and $60^{\circ}$ to $70^{\circ}$ are may be due to background of ITO. Thickness of the films was determined by gravimetric method and ellipsometric measurements. Lattice constant $\mathrm{a}=0.3615 \mathrm{~nm}$ for cubic copper [16]. XRD studies of the films deposited from the bath with $\mathrm{pH}$ values 5.0 have been carried out, The average crystal grain size was estimated from the full width at half maxima of the $\mathrm{Cu}$ peak using the Scherrer equation [17] for the film deposited at different current density;

$$
d=0.9 \lambda / \beta \cos \theta
$$

Where $\lambda$ is the wavelength used $(1.5 \AA)$, the angular line width at half maximum intensity in radians and is the Bragg's angle.

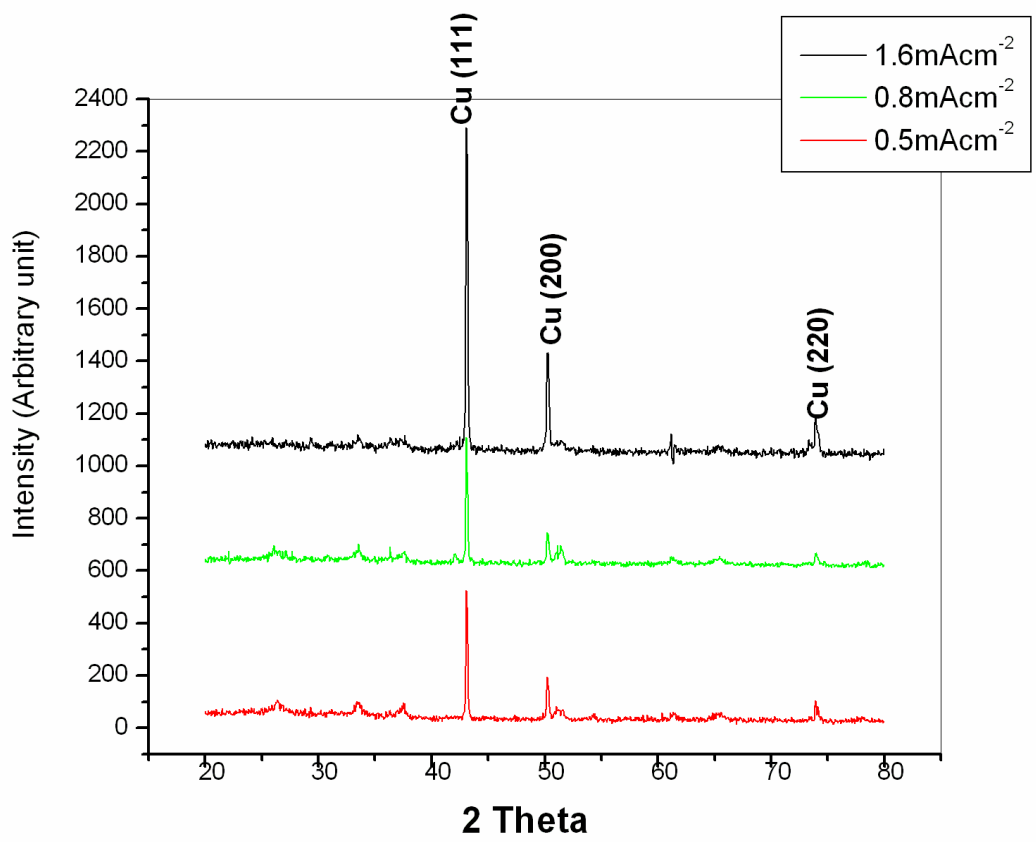

Figure 3.6 XRD pattern of electrodeposited Copper thin films deposited at different current density for 20 minutes

Table 1: Crystal size of $\mathrm{Cu}$ thin films deposited at different current density

\begin{tabular}{|c|c|c|}
\hline Thickness of the film & Average crystal Size & Current density \\
\hline $550 \mathrm{~nm}$ & $16.77 \mathrm{~nm}$ & $0.5 \mathrm{mAcm}^{-2}$ \\
\hline $600 \mathrm{~nm}$ & $17.27 \mathrm{~nm}$ & $0.8 \mathrm{mAcm}^{-2}$ \\
\hline $700 \mathrm{~nm}$ & $19.54 \mathrm{~nm}$ & $1.6 \mathrm{mAcm}^{-2}$ \\
\hline
\end{tabular}


Table 1 shows that as the grain size increases with increase in current density. When the current density is increased, the reduction overpotential also increases, which exponentially enhanced the nucleation rate. At a low current density, the dendritic structure was dominant; however, the nanostructure became granular with increasing current density.

Table2: Optimum bath composition and operating conditions for electrodeposition of thin films of copper.

\begin{tabular}{|c|c|c|}
\hline Bath Composition & Quantity & Operating Condition \\
\hline 1. $\mathrm{CuSO}_{4} .5 \mathrm{H}_{2} \mathrm{O}$ & $0.5 \mathrm{M}$ & Anode: Copper metal (99.99\%) \\
\hline 2. $\mathrm{CH}_{3} \mathrm{COONa}$ & $0.20 \mathrm{M}$ & Cathode: ITO coated glass plate \\
\hline (sodium acetate) & & Temperature: $298-300 \mathrm{~K}$ \\
\hline 3. $\mathrm{NaOH}$ & $1.0 \mathrm{M}$ & Current density: $1.6 \mathrm{mAcm}^{-2}$ \\
\hline 4. $\mathrm{H}_{2} \mathrm{SO}_{4}$ & $\begin{array}{l}\text { Concentrate (adjusting to } \\
\mathrm{pH} \text { ) }\end{array}$ & pH: 5 \\
\hline
\end{tabular}

\subsection{Cyclic Voltammetry}

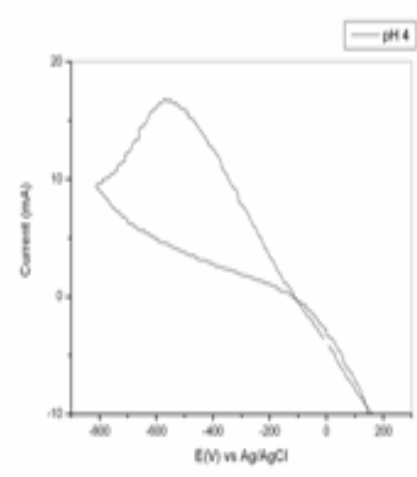

(a)

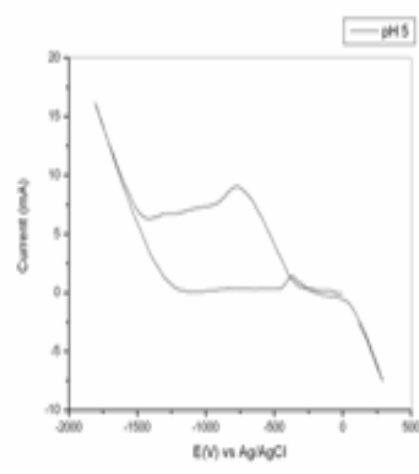

(b)

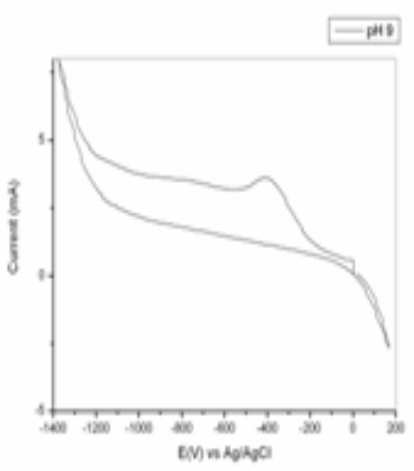

(c)

Figure 3.7 Voltammetric curves for copper electrodeposition at (a) $\mathrm{pH}=4$, (b) $\mathrm{pH}=5$ and (c) $\mathrm{pH}=9$ at scan rate $100 \mathrm{mV} / \mathrm{s}$.

Fig. 3.7 shows the cyclic voltammograms of electrodeposition of thin film of copper at different $\mathrm{pH}$. These curves show that the effect of $\mathrm{pH}$ is responsible for the deposition of the film. At $\mathrm{pH}=4$ no clear deposition peak has been found but at $\mathrm{pH}=5$ sharp deposition peak at current $10 \mathrm{~mA}$ and cathodic potential of $780 \mathrm{mV}$ has formed. If we increase the $\mathrm{pH}$ as shown in Fig. 3.7 (c) current decrease and shift oxidation peak up to more positive potential. In Fig. 3.7 (c) there is no reduction waves of oxygen in the potential range $-1000 \mathrm{mV}$ to $-500 \mathrm{mV}$ this wave shows catalytic reduction of oxygen. The crystals adsorbed oxygen molecules more easily and shows catalytic behavior [12].

\subsection{Electrical conductivity}

The non linear behavior of I-V curves is attributed to inter nanoparticle conduction in these films the electrical conductivity is found to be using two probe method is;

$$
\sigma=I . L / V . A
$$

Where I is current, $\mathrm{L}$ is thickness of the film, $\mathrm{V}$ is the applied voltage and $\mathrm{A}$ is the cross section area of the film. The decrease in conductivity in $\mathrm{Cu}$ thin films is due to contribution of grain boundaries Fig. 3.8 shows the I-V characteristic curves of the thin film of copper. Electrical conductivity for electrodeposited copper films is found to be approximately $960 \times 10^{-10} \Omega^{-1} \mathrm{~m}^{-1}$ for the calculated thickness of the film is $600 \mathrm{~nm}$ at current density $1.6 \mathrm{mAcm}^{-2}$. This value of conductivity is in agreement with the value found from MS model by Juan et al [18] due to size effect at nano scale. Curves shows that resistance is less for the film deposited at pH 5 than film deposited at $\mathrm{pH} 4$ and $\mathrm{pH} 3$ because the crystallinity of the film becomes better at $\mathrm{pH}=5$. The high leakage current of crystalline sample is expected to be due to grain boundaries that serve as high leakage path for the thin films. 


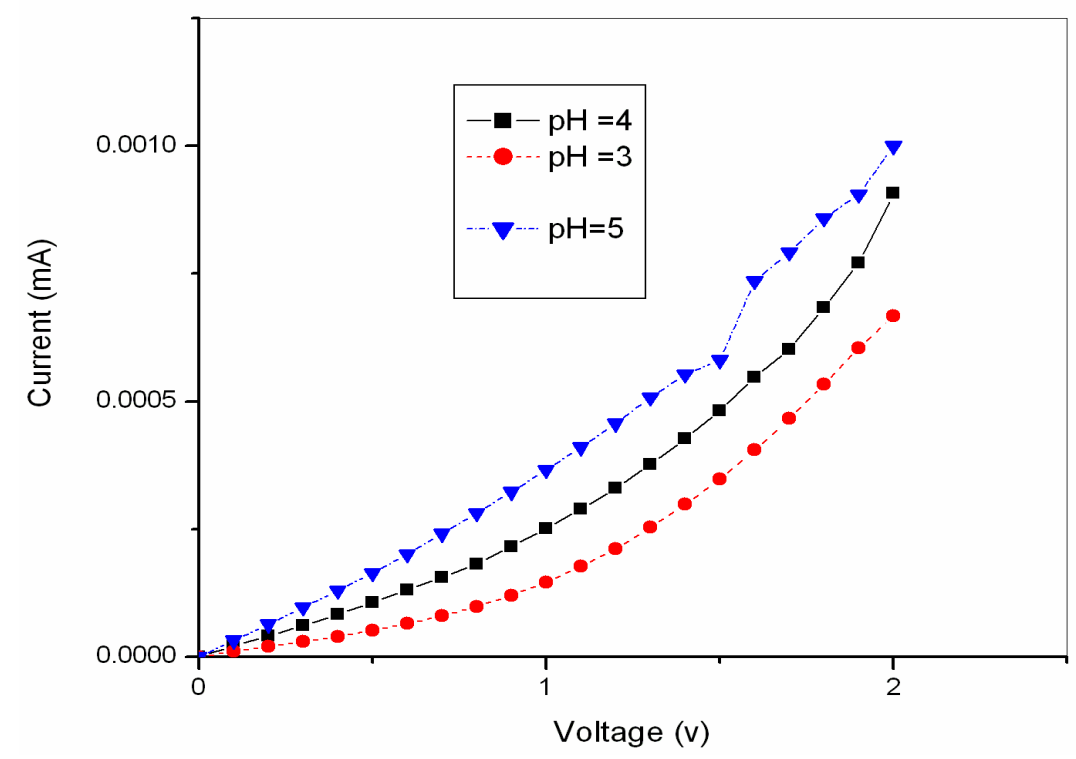

Figure 3.8 I-V Characteristics of electrodeposited copper thin film deposited at different $\mathrm{pH}$

\section{CONCLUSION}

The electrodeposition of nanostructured thin film of copper was investigated here. This study was made to evaluate the influence of nano particle on morphologic and structure characteristics. SEM analysis and voltammetric studies corroborate the mechanism for the reduction process. It was found that deposition time, $\mathrm{pH}$ of the solution and deposition current density all had profound effects on the nucleation mechanism of copper on ITO surface. From XRD it is clear that at $\mathrm{pH} 5$, for current density $1.6 \mathrm{mAcm}^{-2}$ if film is deposited for 20 minutes we get thin film of copper. Electrical conductivity is found to be decreased for electrodeposited copper thin films as compared to bulk material due to size effect.

\section{ACKNOWLEDGEMENTS}

The authors acknowledge the cooperation provided by Principal, Govt. MSJ College, Bharatpur for providing initial basic infrastructure support. The suggestions in Cyclic Voltametric predictions by Prof. P. S. Verma ( Retd. professor in Chemistry, University of Rajasthan, Jaipur) and valuable suggestions on other characterization techniques by Prof. Y. K. Vijay, University of Rajasthan, Jaipur is highly appreciated.

\section{REFERENCES}

[1] W.H. Safranek, The properties of electrodeposited metals and alloys A handbook (New York Elseveir co. 1974) 49.

[2] Luisa Peraldo Bicelli, Benedetto Bozzini, Claudio Mele and Lucia D'Urzo, A Review of Nanostructural Aspects of Metal Electrodeposition, Int. J. Electrochem. Sci., 3, 2008, 356 - 408.

[3] A.Milchev, Electrocrystallization: Fundamentals of Nucleation and Growth, (Kluwer Academic Publishers, The Netherlands, 2002)

[4] M Schlesinger and M Paunovic, Modern Electroplating (John Wiley and sons 5th edition, 2011)9.

[5] A. Mallik and B. C. Ray, Evolution of principle and practice of electrodeposited thin film: A Review on effect of temperature and sonication, International Journal of Electrochemistry 16, 2011.

[6] E. García, Mario Romero-Romo, María Teresa Ramírez-Silva, and Manuel Palomar-Pardavé, Overpotential Nucleation and Growth of Copper onto Polycrystalline and Single Crystal Gold Electrodes, Int. J. Electrochem. Sci., 7, 2012, $3102-3114$.

[7] F A Lowenheim, Modern Electroplating, (J. Wiley and sons, New York, 1974).

[8] Darko Grujicic and Batric Pesic, Electrodeposition of copper: the nucleation mechanisms, Electrochimica Acta 47, 2002, 2901-291.

[9] C.L. Aravinda, S.M. Mayanna and V. S. Muralidharan, Electrochemical behaviour of alkaline copper complexes, Proc. Indian Acad. Sci. (Chem. Sci.), Vol. 112, No. 5,2000, 543-550.

[10] M.R.H. De Almeida, I.A. Carlos, L.L. Barbosa, R.M. Carlos, B.S. Lima-Neto and E.M.J.A. Pallone, Voltammetric and morphological characterization of copper electrodeposition from non-cyanide electrolyte, Journal of Applied Electrochemistry 32, 2002, 763-773.

[11] J.C. Ballesteros, E. Chainet, P. Ozil, Y. Meas and G. Trejo, Electrodeposition of copper from noncyanide alkaline solution containing tartrate, Int. J. Electrochem. Sci., 6, 2011, 2632 - 2651. 
[12] D. K. Yfantis, S. I. Kakos, S. Lamprakopoulos, S. Depountis and C. D. Yfantis, Copper electrodeposition on insulators (plastics) using highly conductive polypyrrole films, Proceedings of the 5th WSEAS International Conference on Environment, Ecosystems and Development, 2006, 190.

[13] J. Mathur and M. Gupta, Nucleation growth of electrodeposited thin film of $\mathrm{Cu}$, Proceedings of DAE SSPS, 2006, 571.

[14] X. J. Zhou, A. J. Harmer, N. F. Heinig, and K. T. Leung, Parametric study on electrochemical deposition of Copper nanoparticles on an ultrathin polypyrrole film deposited on a gold film electrode, Langmuir 20, 2004, 5109-5113.

[15] Udit Surya Mohanty, S. Y. Chen and Kwang-Lung Lin, Nanoscale Electrodeposition of Copper on an AFM Tip and Its Morphological Investigations, Smart nanoparticles technology (174chapter 8, edited by Abbas Hashim, publisher In tech April, 2012).

[16] JCPDS-ICDD 4-836, 1993

[17] A. Guinier, Xray diffraction, (San Francisco, 85, 1994).

[18] Juan M. Camacho and A.I. Oliva, Morphology and electrical resistivity of metallic nanostructures, Microelectronics Journal 36, 2005, 555-558. 